Original Research

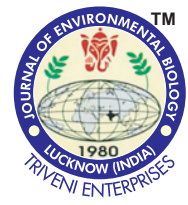

(9) (1)

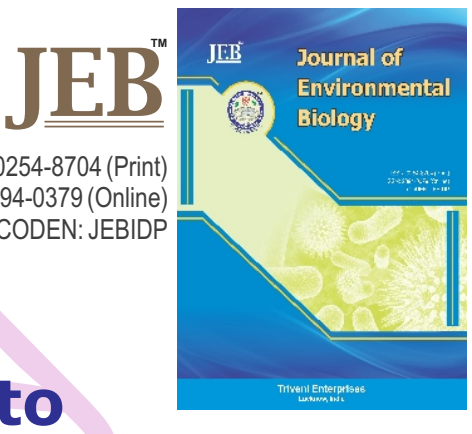

\title{
Application of visible and near infrared reflectance spectroscopy to predict total nitrogen in soil
}

\section{Authors Info}

\section{Z. Tümsavaş}

Department of Soil Science and Plant Nutrition, Faculty of Agriculture, Uludag University, Bursa, 16059, Turkey

*Corresponding Author Email : zeynal@uludag.edu.tr

Key words PLSR analysis, Soil properties, Total nitrogen, Vis-NIR Spectroscopy

Publication Info

Paper received : 25.10.2016

Revised received : 25.06.2017

Accepted : 28.06.2017

\section{Abstract}

Aim : The application and use of precision agriculture technologies targeting reduction in agricultural inputs are associated with various raw data and their assessment to create application maps. Yield mapping and soil mapping are the two basic agricultural application maps for variable-rate applications. Creation of highresolution digital soil maps requires high resolution information. The objective of this study was to predict total nitrogen in soil, using visible and near infrared (vis-NIR) reflectance spectroscopy, which is a new technology used for making fast and accurate measurements of physical and chemical properties of soil.

Methodology : A set of 140 surface soil $(0-20 \mathrm{~cm})$ samples was collected from cultivated land, fruit, and vegetable fields distributed over Bursa province (Turkey). The diffuse reflectance spectra of soil samples were examined for total nitrogen content. Partial least squares regression (PLSR) analysis with full crossvalidation was performed to develop a model for total nitrogen.

Results : The prediction performance of the model produced 0.793 regression coefficient $\left(R^{2}\right), 0.0274 \%$ root mean square errors of prediction (RMSEP) and 2.0802 residual prediction deviations (RPD).

Interpretation : The results showed that the vis-NIR spectroscopy can be used to evaluate soil total nitrogen content. More research should be conducted to improve the model prediction of total nitrogen in soils with both high and low nitrogen content using vis-NIR reflectance spectroscopy.

\section{Total nitrogen prediction}

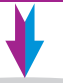

Collecting of soil samples
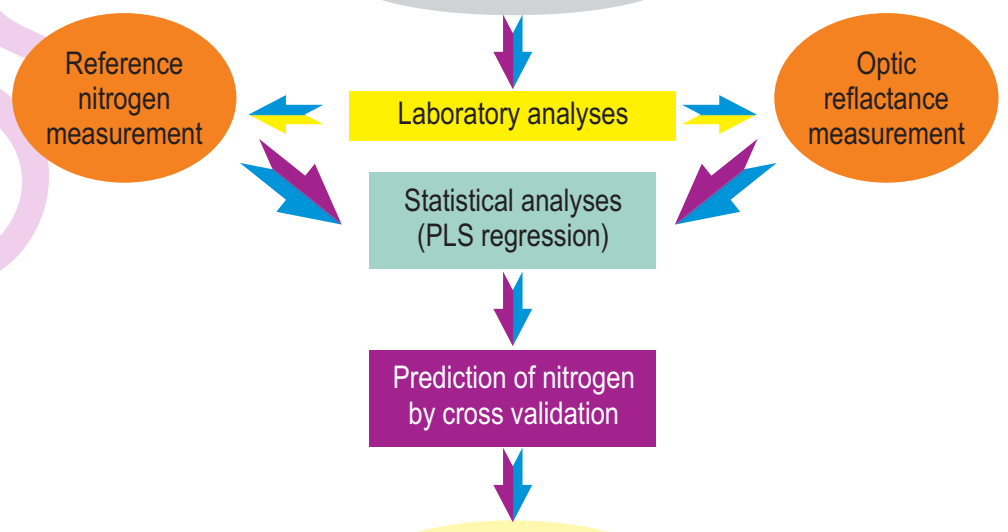

Model development and evaluation 


\section{Introduction}

It is necessary to apply suitable plant and soil management methods to meet the agricultural food demand of increasing world population, in sufficient quality and quantity. Soil is one of the most important components of agriculture, which is defined as the art of getting the highest yield from it using plants as a tool. Conservation and improvement of physical, chemical and biological characteristics of soil are essential to sustain its fertility.

Soil management in conventional agriculture is carried out by utilization of agricultural lands, considering them as homogenous. However, physical and geographical variation of agricultural lands limits the effects of soil management. One of the most important variables in the agricultural lands is soil characteristics. Potential fertility of soil, which shows heterogeneous features and exhibit great variation in terms of soil characteristics even within the same field, can only be achieved by site-specific soil management practices. Although the growers know that they obtain different quantities of yield from different parts of the field or from soils with different textures, they cannot evaluate this knowledge towards production (Vatandas et al., 2005). Precision agriculture is based on knowledge and production integrated with the aim of increasing sustainable production, yield and profitability with minimum effect to the environment. Crop diversity, yield, topographical and meteorological variables are the main parameters to be considered in order to achieve economic agricultural production utilizing knowledge technologies in precision agricultural practices. Precision agriculture components used in determining the existing variables of agricultural production areas consist of global positioning systems, geographical information systems, variable level input applications, and remote sensing. Not only it is aimed to ensure an increase in production via determining the soil characteristics using precision agriculture components, but also to increase the effectiveness of soil management and conservation and to reduce the agricultural input costs.

Determination of soil characteristics through different components, and digital soil mapping are among the most important aspects of precision agriculture applications. Determination of soil characteristics by applying conventional methods with the aim of forming soil maps on local, regional and global basis is a lengthly and costly process (C'ecillon et al., 2009). Therefore it is necessary to develop methods of measurement and analysis that are easy to apply, inexpensive and reliable. In order to realize this aim, studies with visible and near infrared spectroscopic reflections have been accelerated (Ben-Dor and Banin, 1990; Mouazen et al., 2005; Stenberg and Nordkvist, 1996; ViscarraRossel and McBratney, 1998). Basic soil characteristics focused in these researches carried out under laboratory conditions consist of quantity of organic matter, soil texture, clay minerals, as well as structure, plant nutrient elements and microbial activities (Stenberg et al., 2010).

It has been reported that the spectral reflections could be used in the measurements of soil color, ferric oxides, clay minerals, carbonate and organic matter (Viscarra Rossel and Webster, 2011). Spectroscopical methods can be used for evaluating heavy metals existence in soil (Kooistra et al., 2001). The method taken as a basis in the spectrophotometric measurements used for this purpose consisted of obtaining reflection values of samples under laboratory conditions after subjecting them to pre-treatment, and then comparing the values obtained with the physical characteristics analyzed in laboratory. This is followed by the development of a model in which the linear relation is revealed. Soil mapping studies are accelerated by the establishment of the spectral libraries in different countries (Brown, 2007; Terhoeven-Urselmans et al., 2010).

Increasing chemical fertility of soils which is one of the basic principles of suitable soil management is only possible with availability of plant nutrients at suitable ratios, sufficient quantities and in available form. In order to achieve this goal, the nutrient contents of soils should be monitored and the nutrient elements which are not in sufficient quantities should be applied on time and in a balanced manner to every part of the field considering the specific sites, using chemical fertilizers. For this reason, soil analyses are of great importance in the sustainability of chemical fertility of soils.

One of the most important characteristics of soil chemical fertility is total nitrogen content. Nitrogen is a basic resource for the sustainability of world's surface ecosystem and is effects the growth and yield of cultivated plants. For agricultural production it is required in sufficient quantities and consistently in soild uring the growth period of plants. Nitrogen is very mobile (especially $\mathrm{NO}_{3}$ form) in soil and therefore, could easily be washed down via rain or irrigation water and as a consequence, nitrogen content of the soil may fall to insufficient levels. Hence, the nitrogen content of soil should be monitored during the growing period in order to obtain optimum plant growth and crop yield.

The main aim of the present study was to investigate the potential of using vis-NIR reflectance spectroscopy for determining total nitrogen content in soil.

\section{Materials and Methods}

Chemical analysis of soil samples : Soil samples were taken from 140 different points on agricultural soils with different land use types in Bursa province and districts. Soil samples taken from each point in the field were divided into two parts. One part of the soil sample was put in a covered plastic box carrying a label with the location and land information, and stored in a cooler at $4{ }^{\circ} \mathrm{C}$ after being sealed to prevent moisture loss, for use in vis-NIR reflectance spectroscopy measurement. The other part of the soil 
Table 1 : Some descriptive statistics for total nitrogen content of soil samples

\begin{tabular}{ll}
\hline Statistics & Total nitrogen $\%$ \\
\hline Minimum & 0.06 \\
Maximum & 0.34 \\
Mean & 0.15 \\
Standard deviation & 0.05 \\
\hline
\end{tabular}

Table 2 : Evaluation table for model setting over residual prediction deviation (RPD) *

\begin{tabular}{lll}
\hline RPD & Model/Prediction & Application \\
\hline$<1$ & Very poor & Not applicable \\
$1.0-1.4$ & Poor & $\begin{array}{l}\text { Can only be considered for high or } \\
\text { low values }\end{array}$ \\
$1.4-1.8$ & Medium & Evaluation and correlation \\
$1.8-2.0$ & Good & Quantitative evaluation possible \\
$2.0-2.5$ & Very Good & Quantitative model/prediction \\
$>2.5$ & Excellent & Excellent model/prediction \\
\hline
\end{tabular}

${ }^{*}$ compiled from studies of Viscarra Rossel et al. (2006)

Table 3: Statistics for total nitrogen predictions

\begin{tabular}{ll}
\hline Statistics & Result \\
\hline $\mathrm{R}^{2}$ & 0.7930 \\
Standard error of mean & 0.0264 \\
Standard deviation & 0.0570 \\
Root mean square error of prediction (RMSEP) & 0.0274 \\
Residual prediction deviation (RPD) & 2.0802 \\
Slope & 0.8535 \\
\hline
\end{tabular}

sample was put in a nylon bag and labeled and air dried in shade after being transferred to the laboratory. These air-dried samples were sieved using sieves with $2 \mathrm{~mm}$ openings, and then their total nitrogen content was determined using the modified Kjeldahl method (Kacar, 1972).Some statistical values for total nitrogen content of soil samples are shown in Table 1.

Optical measurements : A fibre-optic vis-NIR reflectance spectroscopy (350 - $2500 \mathrm{~nm}$ ) (LabSpec2500 Near Infrared Analyzer, Analytical Spectral Devices, Inc., USA) was used to measure the spectra of the soil samples in diffuse reflectance mode. It had one Si array $(350-1000 \mathrm{~nm})$ and two Peltier cooled InGaAs detectors (1000-1800 nm and 1800-2500 nm). The sampling interval of the instrument was $1 \mathrm{~nm}$; however, the spectral resolution was $3 \mathrm{~nm}$ up to $700 \mathrm{~nm}$ wavelength and $10 \mathrm{~nm}$ in the range of $1400-2100 \mathrm{~nm}$ wavelength.

The most important stage to obtain valid results regarding vis-NIR absorption spectroscopy reflections on the pretreated soil samples is before the reflection values were taken. Pretreatments were drying, crush-grinding and sieving. Avoiding use of chemicals in pretreatments and rapid realization of measurements within a few seconds are among the advantageous aspects of this method (Stenberget al., 2010).Before spectra measurements, each soil sample was passed through a sieve in a $2 \mathrm{~mm}$ diameter after the crushgrinding process and then put into plastic containers; the surface was smoothed with a spatula. Soil samples in plastic containers were placed so as to be in touch with the high intensity light source of the spectroscopy. Three different spectroscopic measurements were made for each soil sample and then the means of these 3 measurement values were taken.

Statistical analysis of the reflection values : Doing statistical analyses by comparing the spectral reflection values with total

nitrogen reference values obtained by pretreatment and forming a model is required. The Unscrambler® (Version 9.8, Camo A/S, Oslo, Norway) software was used for the statistical analyses and to develop a model. In order to form a better model from the reflection values, they were subjected to statistical preliminary processes. Attempt was made to obtain best regression results by applying different preliminary processes to the reflection values. The wavelengths obtained in the vis-NIR spectroscopy used were $350-2500 \mathrm{~nm}$. The statistical preliminary process starts with the reduction of wavelength numbers. For this purpose, the beginning values 350-399 $\mathrm{nm}$ and values of 2251-2500 $\mathrm{nm}$ were omitted with the aim of decreasing the noise. Later on, the average of every five data was taken and they were grouped, hence the data column to be analyzed was limited to 226 . After the determination of wavelength number, the processes of normalization, Savitzky-Golay first derivative and smoothing were applied to the spectral reflection values (Savitzky and Golay, 1964). Distribution of the data obtained by applying normalization preliminary process to the original reflection values are given in Fig. 1.

Taking $1^{\text {st }}$ degree derivative is being used as a method to eliminate the irregularities in reflection data. Smoothing process is applied for the leveling of positive and negative peak points. Distribution of the data obtained as a result of smoothing and Savitsky-Golay $1^{\text {st }}$ derivative applied following normalization is shown in Fig. 2.

Model establishment : Although it has been reported in several studies that multivariate methods could be used in the statistical analyses related to the reflection values, it was pointed out by many researchers that the PLSR method gave higher correlated results (Chang et al., 2001; Bogrekci and Lee, 2004; Mouazen et al., 2006).In the PLSR method, the explanatory variables which have multiple linear correlation in between, can clarify both the change in the dependent variables and the change in the clarifying variables through algorithms (Bulut and Alın, 2009). The initial stage of model establishment is dividing the sample spectra to $80 \%$ calibration and $20 \%$ validation groups. After this process, the calibration group is subjected to different statistical methods and the $R^{2}$ value is calculated. It is aimed to obtain the calibration 


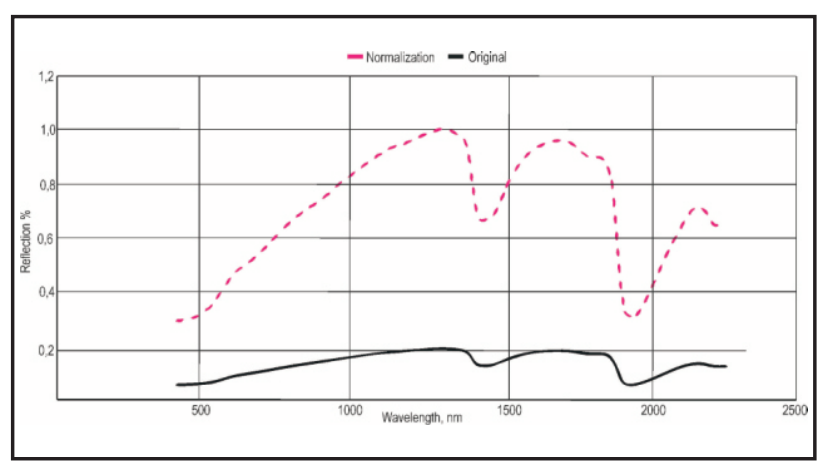

Fig. 1 : Distribution of the original data and the data obtained as a result of normalization process

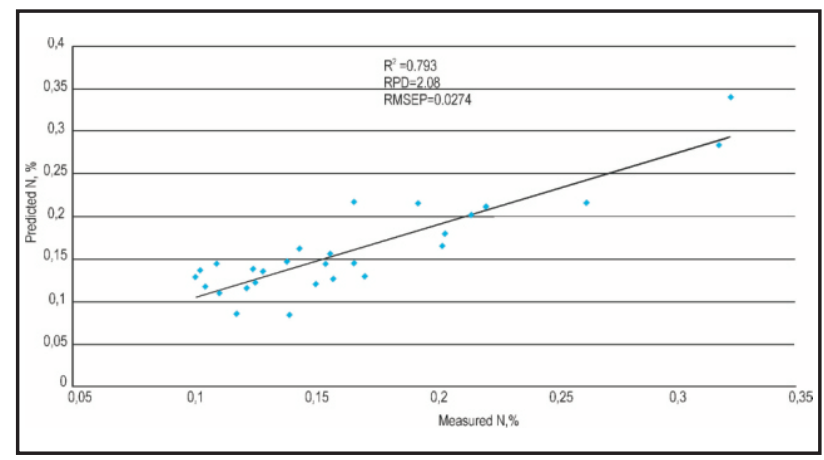

Fig. 3 : Distribution of measured and predicted total nitrogen

model by applying cross validation between the validation group and calibration group. In this study which was conducted for total nitrogen determination, 140 soil samples were randomly divided into 112 calibration and 28 validation groups.

Statistical evaluation of the model : $R^{2}$ alone is not sufficient for validation of calibration model. For this purpose, it is preferred to evaluate the RMSEP (Equation 1) and RPD (Equation 2), together with $R^{2}$, as an indication of the validity of the model (ViscarraRosseletal., 2006).

$$
\text { RMSEP }=\sqrt{\left[\frac{\left\{\sum_{i=1}^{n} d_{i}^{2}\right\}}{n}\right]}
$$

Here;

$\mathrm{n}$ : Number of data

d: Difference between reference measurement and prediction values

$$
\mathrm{RPD}=\frac{\text { Standard deviation }}{\text { RMSEP }}
$$

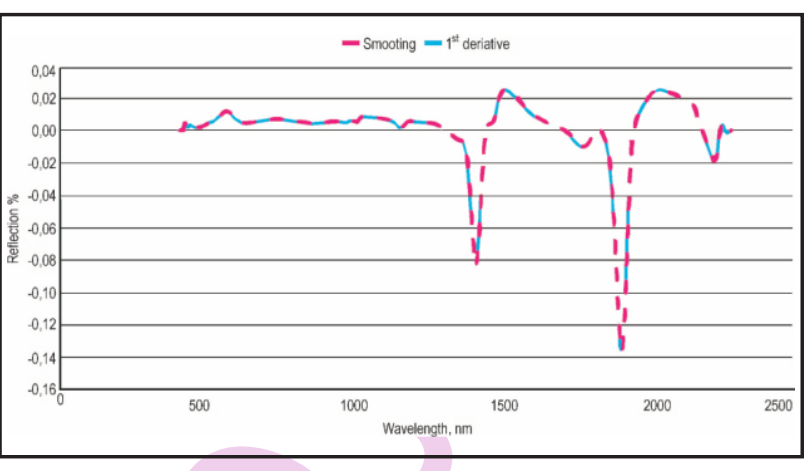

Fig. 2 : Distribution of the data obtained via 1 st derivative and smoothing process

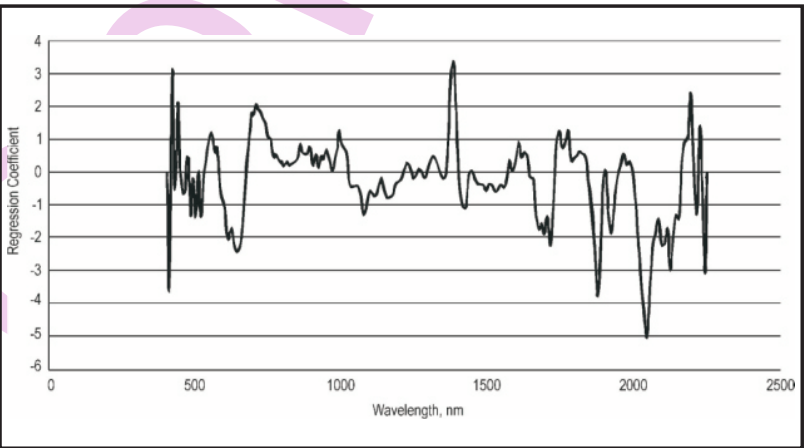

Fig. 4 : Scatter plot of regression coefficient values according to wavelength for predicting total nitrogen

For a successful correlation of agricultural analyses, it is desirable to have $R^{2}>0.95$ and $R P D>5$. Nevertheless, it is difficult to obtain these results for materials such as soil having a heterogeneous nature. The RPD values are classified as: RPD< 1.0: very poor model predictions and their use is not recommended; RPD between 1.0 and 1.4: poor model predictions, where only high and low values are distinguishable; RPD between 1.4 and 1.8: fair model predictions, which may be used for assessment and correlation; RPD values between 1.8 and 2.0: good model predictions, where quantitative predictions possible; RPD between 2.0 and 2.5 : very good, quantitative model predictions; and RPD > 2.5: excellent model predictions (Viscarra Rossel et al., 2006).

The results obtained in this study were evaluated based on this classification system. Evaluation of model according to the RPD values are given in Table 2 .

\section{Results and Discussion}

Studies on the utilization of vis-NIR spectroscopy reflection for the prediction of physical and chemical characteristics of soil continue to increase. The PLSR calibration 
models were proposed and tested to predict soil organic carbon and total nitrogen concentrations (Reeves et al., 2006; Cozzolino and Moro'n, 2006; Barthe's et al., 2008; Vasques et al., 2009).In this study, spectroscopy reflection values related to the prediction of total nitrogen values were examined. Results of the statistical evaluation are given in Table 3 . The total nitrogen laboratory results belonging to soil samples taken from 140 points were compared with spectroscopy reflection results and their predictability was assessed. As can be seen in Table 3, $R^{2}$ regression value was found as 0,793 and residual prediction deviation value as 2.0802 . $R^{2}$ and the RPD values calculated in this study for the prediction of total nitrogen were lower than that of previous studies (Xie et al., 2011; Wenjun et al., 2014). Many researchers have reportedsuccessful application of thevis-NIR spectroscopy for the prediction of various soil characteristics. In terms of predicting total nitrogen content, Yang et al.(2011) stated that the best predictions $\left(R^{2}>0.90\right.$ and $\left.R P D>3.3\right)$ were achieved for total nitrogen using the visible range $(400-700 \mathrm{~nm})$. Xieet al. (2011) estimated total nitrogen content of soil with-high coefficient $\left(R^{2}=0.97\right)$ using infrared (NIR) spectra. In another study, prediction accuracy of total nitrogen with laboratory-based soil spectra using the PLSR method was $R^{2}$ of 0.87 and RPD of 2.81 (Wenjun et al., 2014). The successful prediction of soil total nitrogen is mainly due to the nitrogen's direct spectral responses to the overtones and combinations of $\mathrm{N}-\mathrm{H}, \mathrm{C}-\mathrm{H}+\mathrm{C}-\mathrm{H}$ and $\mathrm{C}-\mathrm{H}+\mathrm{C}-\mathrm{C}$ in the vis-NIR spectra (Stenberg et al., 2010; Kuang et al., 2012).

Calibration model was established by applying cross validation between validation group and calibration group. Graph related to measured total nitrogen and predicted total nitrogen values obtained from 28 validation groups is given in Fig. 3 .

$\mathrm{R}^{2}$ graphics is useful in observing the wavelengths, which is important for predicting the total nitrogen (Fig. 4). Important peak points can be seen in the figure, especially in the wavelengths of $408 \mathrm{~nm}, 420 \mathrm{~nm}, 1384 \mathrm{~nm}, 11874 \mathrm{~nm}$ and $2044 \mathrm{~nm}$.

In conclusion, the PLSR analyses with full crossvalidation were performed to establish model for total nitrogen. $R^{2}$ and RPD values were found as 0.793 and 2.0802 , respectively. These results demonstrated that a very good level of correlation was obtained according to the RPD values. However, studies for developing models to evaluate the effect of factors such as color, texture, organic matter content, lime, moisture content on the reflection values should also be carried out. The results showed that the vis-NIR spectroscopy can be used to evaluate soil total nitrogen content. More research should be conducted to improve the model prediction of total nitrogen in soils with both high and low nitrogen content using vis-NIR reflectance spectroscopy.

\section{References}

Barthe `s, B.G., D. Brunet, E. Hien, F. Enjalric, S. Conche, G.T. Freschet, R. D'annunzio and J. Toucet-Louri: Determining the distributions of soil carbon and nitrogen in particle size fractions using nearinfrared reflectance spectrum of bulk soil samples. Soil Biol. Biochem., 40, 1533-1537 (2008).

Ben-Dor, E. and A. Banin: Near-infrared reflectance analysis of carbonate concentration in soils. Appl. Spectrosc., 44, 1064-1069 (1990).

Bogrekci, I. and W.S. Lee: Spectral signatures of common phosphate in soils and their effect on absorbance spectra of soil samples with different phosphorus concentration. ASAE/CSAE Annual International Meeting, Ottawa, Ontario, Canada, 1-11 (2004).

Brown, D.J.: Using a global VNIR soil-spectral library for local soil characterization and landscape modeling in a $2^{\text {nd }}$-order Uganda watershed. Geoderma, 140, 444-453 (2007).

Bulut, E. and A. Alin: Comparison of partial least squares regression method algorithms: Nipals and PLS-Kernel and an application. Dokuz Eylul University, Faculty of Economics and Administrative Sciences Journal, 24, 127-138 (2009).

C'ecillon, L., B.G. Barthes, C. Gomez, D. Ertlen, V. Genot, M. Hedde, A. Stevens and J.J. Brun: Assessment and monitoring of soil quality using near-infrared reflectance spectroscopy (NIRS). Europ. J. Soil Sci. 60, 770-784 (2009).

Chang, C.W., D.A. Laird, M.J. Mausbach and C.R. Hurburgh: Nearinfrared reflectance spectroscopy-principal components regression analyses of soil properties. Soil Sci. Soc. Am. J., 65, 480-490 (2001).

Cozzolino, D. and A. Moro'n: Potential of near-infrared reflectance spectroscopy and chemometrics to predict soil organic carbon fractions. Soil Till. Res., 85, 78-85 (2006).

Kacar, B.: Chemical Analyses of plant and soil. $2^{\text {nd }}$ Plant Analyses.Publications of Agricultural Faculty of Ankara University, Publication Number.453, Practice guide.155, Ankara, (1972).

Kooistra, L., R. Wehrens, R.S.E.W. Leuven and L.M.C. Buydens: Possibilities of visible-near-infrared spectroscopy for the assessment of soil contamination in river floodplains. Analytica ChimicaActa, 446, 97-105 (2001).

Kuang, B., H.S. Mahmood, Z. Quraishi, W.B. Hoogmoed, A.M. Mouazen and E.V. Hanten: Sensing soil properties in the laboratory, in-situ, and on-line. AReview. Adv. Agron, 114, 155-223 (2012).

Mouazen, A.M., J. De Baerdemaeker and H. Ramon: Towards development of on-line soil moisture content sensor using a fibretype NIR spectrophotometer. Soil Till. Res., 80, 171-183 (2005).

Mouazen, A.M., R. Karoui, J. De Baerdemaeker and H. Ramon: Characterization of soil water content using measured visible and near infrared spectra. Soil Sci. Soc. Am. J., 70, 1295-1302 (2006).

Reeves, III, J.B., R.F. Follett, G.W. McCarty and J.M. Kimble: Can near or mid-infrared diffuse reflectance spectroscopy be used to determine soil carbon pools? Communic.in Soil Sci. Plant Analy., 37, 2307-2325 (2006).

Savitsky, A. and M.J.E. Golay: Smoothing and Differentiation of data by simplified least squares procedures. Analy. Chem., 36, 1627-1639 (1964).

Stenberg, B. and E. Nordkvist: Near infrared reflectance measurements to assess the chemical and physical variations in arable soils. In: Near Infrared Spectroscopy: The Future Waves. (Eds.: A.M.C. Davies and P. Williams) NIR Publications, Chichester, UK/Montreal, Canada, pp. 498-504 (1996).

Stenberg, B., R.V. Rossel, A.M. Mouazen and J. Wetterlind: Near infrared spectroscopy for soil analysis in practical agriculture, forestry and environmental monitoring. Advan. Agron., 107, 163- 
$215(2010)$

Terhoeven-Urselmans, T., T.G. Vagen, O. Spaargaren and K.D. Shepherd: Prediction of soil fertility properties from a globally distributed soil mid-infrared spectral library. Soil Sci. Soc. Am. J. 74, 1792-1799 (2010).

Vasques, G.M., S. Grunwald and J.O. Sickman: Modeling of soil organic carbon fractions using visible near infrared spectroscopy. Soil Sci. Soc. Am. J. 73, 176-184 (2009).

Vatandas, M., M. Guner, and U. Turker: Precision farming tecniques. Union of Chambers of Turkish Engineers and Architects. The Chamber of Agricultural Engineers, $6^{\text {th }}$ Technical Congress, January 3-7, Ankara, pp.347-365, (2005).

ViscarraRossel, R.A. and A.B. Mcbratney: Laboratory evaluation of a proximal sensing technique for simultaneous measurement of soil clay and water content. Geoderma, 85, 19-39 (1998).

ViscarraRossel, R.A., D.J.J. Walvoort, A.B. Mcbratney, L.J. Janik and
J.O. Skjemstad: Visible, near infrared, mid infrared or combined diffuse reflectance spectroscopy for simultaneous assessment of various soil properties. Geoderma, 131, 59-75 (2006).

ViscarraRossel, R.A. and R. Webster: Discrimination Australian soil horizons and classes from their Visible-near infrared spectra. Eur. J. Soil Sci., 62, 637-647 (2011).

Wenjun, J., S. Zhou and H. Jingyi: In situ measurement of some soil properties in paddy soil using visible and near-infrared spectroscopy. Plos one, 9, 1-11 (2014).

Xie, H.T., X.M. Yang, C.F. Drury, J.Y. Yang and X.D. Zhang: Predicting soil organic carbon and total nitrogen using mid- and near-infrared spectra for brookston clay loam soil in southwestern Ontario, canada. Can. J. Soil Sci., 91, 53-63 (2011).

Yang, H., B. Kuang and A.M. Mouazen: Prediction of soil TN and TC at a farm-scale using VIS-NIR spectroscopy. Adv. Mater. Res., 225226, 1258-1261 (2011). 